VI.-Sixth period, comprising six days. Drink restricted to twenty ounces of milk + nine drachms of mixture $=597 \cdot 7 \mathrm{cc}$. Drugs given: three drachms of quinine-and-iron mixture three times a day. Bowels open in normal manner.

\begin{tabular}{|c|c|c|}
\hline Date. & $\begin{array}{l}\text { Cubic centimetres of } \\
\text { fluid taken in } \\
\text { preceding } 24 \\
\text { hours. }\end{array}$ & $\begin{array}{l}\text { Cubic centimetres of } \\
\text { urine passed in } \\
\text { preceding 24 } \\
\text { hours. }\end{array}$ \\
\hline November 29 th & $597 \cdot 7$ & 580 \\
\hline 30th & $597 \cdot 7$ & Not estimated. \\
\hline December 1st & $597 \cdot 7$ & 500 \\
\hline $2 n d$ & $597 \cdot 7$ & 660 \\
\hline $3 r d$ & $597 \cdot 7$ & 450 \\
\hline Ath & $597 \cdot 7$ & 690 \\
\hline
\end{tabular}

Average daily quantity of urine passed for fve days (measurement being accidentally omitted one day) on $597 \cdot 7 \mathrm{cc}$. of drink $=576 \mathrm{cc}$. Average daily excess of inflow by drink over outflow by urine $=21.7 \mathrm{ec}$.

The preceding was one of a curious group of cases which I have met with occasionally in children, characterised by effusion into the peritoneal cavity, with gradual reabsorption of the fuid, and recovery after a protracted period. The causes of the dropsy are, to my mind, still a matter of doubt; it is usually attributed to tubercular peritonitis, sometimes to portal obstruction, and sometimes to malarial infiuence. In the present case the definite commencement of the illness, with the absence of any sign of hepatic lesion, would seem to indicate a subacute inflammatory affection of the peritoneum, probably of a simple and not tubercular character. But, whatever the cause, a large quantity of foid had accumulated in the abdominal cavity, and this entirely disappeared in the course of twenty-seven days. The process of reabsorption was less rapid than in the preceding cases, but it is in accordance with my experience that dropsies of the peritoneum are, as a rule, more slowly semoved than those of the pleura or the cellular tissue.

It will be seen from the table that the restriction of drink to twelve ounces was followed by an increase in the quantity of urine compared with the average amount for two days previously on an unlimited supply of drink. The relation between the inflow and outflow was, moreover, reversed, the latter being on an average 64.4 cc. in excess of the former, instead of the usual deficiency of $200 \mathrm{cc}$. In the present case the difference was probably still greater, for if the child drank the low average quantity of thirty ounces= 349 co. when unrestricted, the average flow of urine being only 365 co., the deficiency of outflow as compared with inAlow would be no less than 484 cc. But taking merely the average amount of 200 cc. deficiency, the gain in drainage by urine after the restriction would be not less than 264 cc. It must be remarked that this result was coincident with the administration of digitalis, and was probably largely due to the influence of the drug.

The Eurther reduction of drink caused a fall in the quantity of urine, but the relation between inflow and outflow remained almost unchanged, the excess of the latter, on an average for five days, being $63 \cdot 3 \mathrm{cc}$., as compared with $60^{\circ} 4$ for the previous five days. The substitution of a mixture of bitasstrate of potash and scoparium for the digitalis and Iron was, however, followed by an immediate and persistent diminution in the gross amount of urine, and also by a distinct loss of drainage-the excess of outflow over inflow faling to an average of only $6.6 \mathrm{cc}$; and this coincidence, taken with the preceding coincidence of an increase of drainage with the administration of digitalis, is very striking and significant. Throughout, however, as in the preceding cases, the proportion of fluid excreted to fluid swallowed was greater than under ordinary conditions, and this reached its highest point in the present instance-i.e., the drainage was greatest - when drink was reduced to the lowest amounts, the results being almost identical for twelve and nine ounces.

( $T$ o be concluded.)

Vaccination Grant.-Dr. Davies, of Wrexham, hes received an award of $28217 \mathrm{~s}$. for efficient vaccination in bis district.

\section{INTRACRANIAL SARCOMATOUS TUMOUR IN CONNEXION WITH THE} AUDITORY NERVE.

\author{
B Y G E R G E P. FI E L D, \\ AURAL SUBGBON TO ST. MARY'S HOSPITAL.
}

E. J-, aged twenty-nine, was admitted into St. Mary's Hospital January 29th, 1877, under Dr. Broadbent's care. History imperfect. Has suffered from pain in the head and vomiting, and recently vision has been failing. Complains of her head throbbing; says that she saw very little yesterday, and cannot see at all to-day. Has great trouble in swallowing. Is very deaf and slow to answer. Food trickles from corner of mouth. Pulse 75 , feeble; temperature $97.5^{\circ}$. Is sick at times. Bowels open. Ordered a drachm and a half of solution of perchloride of mercury in an ounce of camphorated water three times a day.

February 3rd.-Rather better. Can see a little. Pain in the forehead; giddy. Marked paralysis of right side of face, and impairment of power in right limbs. Sensation about the same on the two sides. On ophthalmoscopic examination double optic neuritis was seen to be present in an advanced stage, with consecutive atrophy.

It was difficult to determine whether the deafness was due to defect in the auditory apparatus or to hebetude, and impossible to say which ear was the worse.

5th.-At 5 P.M. yesterday she became unconscious a short time. Made a roaring noise in the throat. Right leg drawn up. Right arm flexed and hand clenched. Right extremities generally rigid. Frothed at mouth.

6 th.-Fingers of right hand contracted. Sensaticn equal in both hands and on both sides of face and trunk. Tongue deflected to right side more than usual. Food clinging to the teeth. Left eye turned further inwards. Slept well. Complains that she cannot see at all. Pulse 76 ; temperature $98 \cdot 2^{\circ}$. Facial paralysis increased.

When the patient was made to walk it was seen that there was not merely dragging of the right leg, but a want of control over both lower extremities, and a vagueness in their movements highly suggestive of disease in the cerebellum. The cross-paralysis-namely, of the sixth nerve on the left side and of the face and limbs on the right side-appeared to localise the cause as affecting the left side of the pons, and the ataxy of the lower limbs showed the cerebellum to be interfered with. The concurrence of pain in the head, vomiting, and double optic neuritis pointed to tumour as the probable disease; but it was difficult to understand how a tumour outside the pons should compress only the sixth nerve; and, had the morbid condition been in the pons, it could scarcely affect the nucleus of the sixth nerve without involving that of the seventh.

9th.-Rather better, but drowgy. Winks if a finger be pnt near the right eye, but the left eye may be almost touched without causing winking.

12th.-About 11 A.Mr., she had a fit, with gurgling in the throat ; was unconscious about ten minutes; about 4 P.M. a second similar attack, lasting about the same time, occurred; about 7 P.M. a third similar fit. Skin cold during fits. Deafness increased; sleeps at night; cannot grasp with the right hand.

15th.-Looks better; complains of pain in the forehead, and is still more deaf ; food and saliva hanging about lips and teeth. Temperature $98^{\circ}$.

19th. - Last night fell into a torpid state at 6 P.M., and continued so until 4 A.M. About 11 A.M. she fell into a similar condition; lies on her back, with her mouth open up and down movement of tongue; not roused by touching eyeballs; limbs extended; pulse 86, regular. About 9 P.M. she fell into the same kind of stupor till 4 A.M., and remained in a drowsy state; much more deaf; passes motions unconsciously; right hand almost powerless; articulation indistinct.

21 st.-Has not been torpid again; answers slowly; urine cloudy, sp. gr. 1031 ; face $\mathbf{s w o l l e n , ~ m o r e ~ e s p e c i a l l y ~ o n ~ r i g h t ~}$ side, but no pain in it.

March 1st.-Pulse 61 ; face very red; very deaf; irregular movement of fingers of left hand; temperature $97^{\circ}$; diarrhoa; urine contains mucus, sp. gr. 1024. 
6th.-No diarrbca; same condition as before, but rather less deaf.

8th.-Dark red patches under both eyes; mouth rather more deflected to right side.

13 th.-Not so well.

19th.-Torpid and semi-conscious; raves for her meals; breathing rather stertorous.

23rd. - Does not answer questions; passes motions in bed; left eyeball kept closed; right eye half open.

April 17th.-For the last month has remained very much in the same condition; she is quite blind and very deaf; cries out violently for food at stated intervals; the whole fundus of both eyes slaty in colour ; the intellectual function is destroyed. On April 29th she died.

At the post-mortem examination, which was carefully made by Dr. Mahomed, a tumour of the size of a Maltese orange was found attached to the posterior surface of the right petrous bone, ${ }^{1}$ just above the internal meatus. It was

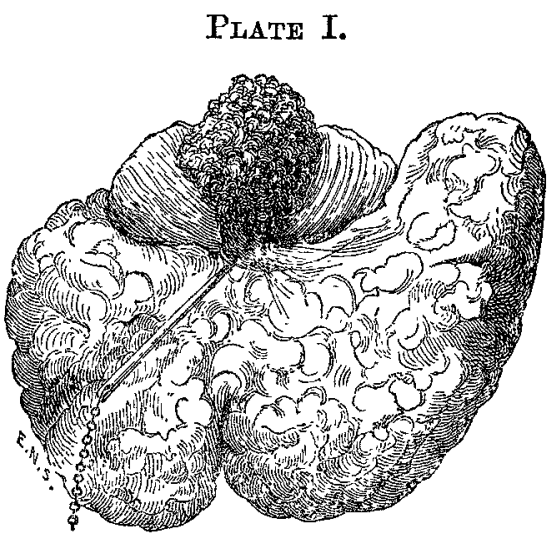

fissured and corrugated on itg surface, like the cerebellum, and was of soft sarcomatous structure, not unlike braintissue on section. The upper margin of the medulla formed its posterior boundary. On examination of the petrous bone, the tumour was found to spring from the internal auditory meatus, taking origin apparently from the dura mater lining the meatus, and unsheathing the auditory nerve. The tumour did not extend into the meatus. On

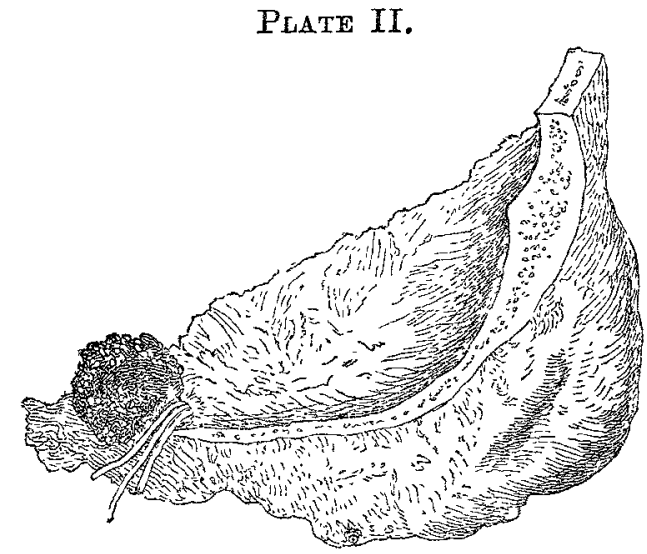

microscopic examination the tumour proved to be a sarcoma. It consists of roued-celled sarcomatous tissue (granulation sarcoma), which tends to arrange itself in whorls, in the centre of which bloodvessels are generally found. The contents of some of these spaces could not be distinctly made out ; they much resembled " giant cells." The tumour is very vascular ; the vessels, however, have not thick walls. It presents the appearance of a tumour of moderately rapid growth, not so quick as in the case of most malignant growths, nor so slow as many benign ones.

Remarks. - This oase is of interest both from its clinical and pathological aspects. I have recorded it chiefly on

1 These pathological specimens were exhibited at the anvual museum of the British Medical Association at Manchester, and thus described in the the British Medical Association at Manchester, and thus described in the Catalogue :- Plate I. A cerebral tumour, which took origin from the propressed so as to completely flatten out, and apparently destroy, the right pressed so as to completely flatten out, and apparently destroy, the right right middle peduncle of the cerebellum. It consists of round-eelled sarcomatous tissue-granulation garcoma.-Plate II. Petrous bone, showing origin f the takin of the above tum. It springs from the internal auditory meatus, sheathing the auditory nerre. account of its value as a rare lesion in connexion with the auditory nerve. When it came under observation the symptoms were too far advanced for a diagnosis of its exact origin to be possible. Dr. Hughlings Jackson has remarked that deafness is a very rare symptom of intracranial disease. unless associated with a lesion of the organ of hearing; and Roosa, in an exhaustive summary (which includes also the experience of Toynbee) of the causes of so-called nervous deafness, only mentions one case of tumour of the auditory nerve, which occurred in a deaf-mute, and was recorded by Duverney, and of this case, moreover, no details are given. Lower Seymour-street.

\section{A}

\section{HOSPITAL PRACTICE, BRITISH AND FOREIGN.}

Nulla autem est alia pro certo noscendi via, niai quamplarimas et morboram et dissectionum historias, tum aliorum, tum proprias collectas habere, $\mathrm{e}$ inter se comparare.-MLorgagri De Sed. et Caus. Morb., lib. iv. Procmium.

\section{KING'S COLLEGE HOSPITAL.}

CASE OF STRANGULATED FEMORAL HERNIA ; RELIEF AND RADICAL CURE BY OPERATION.

(Under the care of Professor Wood.)

Fon the notes of the following case we are indebted to Mr. Edward Ground, surgical registrar.

H. S—, aged fifty years, a widow, was admitted on Saturday, Oct. 27th, 1877, suffering from strangulated femoral hernia on the left side. About five years previously she noticed a small swelling in the left groin. This caused no pain or inconvenience, but gradually increased in size, and never disappeared entirely. She never wore a truss for it. Two days before admission she was seized with intense pain about the region of the hernia and abdomen, followed soon afterwards by vomiting of bilious matters. For ten days before admission she had passed nothing by the bowels.

On admission, she complained of intense pain in the left groin and left iliac region; the pulse was rapid and feeble: face dusky; eyes sunken; tongue brown and dry; vomiting occurred occasionally, being readily excited by the introduction into the stomach of any substances, such as milk or beef-tea; the vomited matters never became stercoraceous; constipation was complete, purgatives given by the mouth and copious enematia producing no result. On examining the left groin an elongated swelling, irregular in outline, and about the size of a hen's egg, was. found, commencing about one inch below Poupart's ligament, internal to the femoral vessels, and external to tho pubic spine on that side, and extending upwards and outwards over Poupart's ligament. This was hard, lobulated, and elastic, with a total absence of any impulse on coughing. Percussion produced a dull note over the greater part of the tumour.

The patient was placed under the influence of chloroform, and the taxis, combined with involution of the patient, applied by Mr. Wood, but without causing reduction. An incision was then made about three inches in length, commencing below, over the neck of the hernia, and carried upwards and outwards over its body. The various coverings of the hernia were divided, and the sac opened. The hernia consisted chiefly of omentum, but a knuckle of chocolatecoloured intestine was found strangulated in the crural canal, behind the mass of omentum. Gimberrat's ligament having been divided upwards and inwards for about two lines, the intestine was drawn down and examined, but, being free from ulceration or gangrene, was returned into the abdominal cavity. The omentum external to the crural canal was then cautiously cut with blunt scissors, and the bloodvessels ligatured separately. The stump of the omental mass was left in the crural canal, and tucked into the opening through which the bowel had descended. Mr. Wood then passed the left index finger into the crural canal pushing before it the stump of omentam, and lifting up 